'Students' Scientific Association by the Institute of Pathophysiology of the Chair of Pathophysiology and Endocrinology, School of Medicine with the Division of Dentistry in Zabrze, Medical University of Silesia in Katowice

${ }^{2}$ Chair of Pathophysiology and Endocrinology, School of Medicine with the Division of Dentistry in Zabrze, Medical University of Silesia in Katowice

\title{
Rare cases of bezoars in the urinary tract of diabetic patients - a review of case reports
}

\begin{abstract}
Bezoars are spherical conglomerates of foreign bodies or food debris, typically occurring in the gastrointestinal tract, primarily in the stomach. In exceptionally rare cases bezoars may also form within the urinary tract. In such cases, their formation is a result of an ongoing fungal infection in the urinary tract or a systemic infection, and the bezoar is most often composed primarily of hyphae, mostly of species Candida albicans, and fragments of necrotic tissue. Chronic hyperglycaemia impairs natural defence mechanisms of the immune system, both cellular as well as humoral, and thus predisposes towards fungal infections. This paper discusses selected examples of cases of fungal bezoars in the urinary tract in diabetic patients described to date, with an emphasis on risk factors for their formation and treatment methods. (Clin Diabetol 2016; 5, 4: 131-137)
\end{abstract}

Key words: diabetes mellitus, bezoars, urinary tract, Candida albicans, Aspergillus

\section{Introduction}

Bezoars are spherical, compact bodies occurring in animals and, occasionally, in humans. They are most

Address for correspondence:

Paweł Jonczyk

STN przy Zakładzie Patofizjologii Katedry Patofizjologii i Endokrynologii Wydział Lekarski z Oddziałem Lekarsko-Dentystycznym

Śląskiego Uniwersytetu Medycznego w Katowicach

pl. Traugutta 2, 41-800 Zabrze

e-mail: pawel.jonczyk@med.sum.edu.pl

Translation: GROY Translations

Clinical Diabetology 2016, 5, 4, 131-137

DOI: $10.5603 /$ DK.2016.0023

Received: 14.05.2016

Accepted: 07.07.2016 often located in the gastrointestinal tract (stomach, oesophagus, rectum). Depending on materials of which they are composed, the following main types of bezoars can be distinguished: phytobezoars (plant debris), trichobezoars (hair) and pharmacobezoars (undigested medication) [1]. They can also be found, albeit extremely rarely, in the urinary tract. There, they form as a result of conglomerate deposition and excessive growth of hyphae, mostly of genera Candida and Aspergillus. Primary factors predisposing towards their formation include: diabetes, immunosuppression, chronic diseases and malignant neoplasms, as well as congenital and acquired immunodeficiencies or glucocorticosteroid therapy. More than half of cases of fungal bezoars in the urinary tract is casued by Candida albicans infection. Under physiological conditions, it is a commensal organism in the initial and final segments of the gastrointestinal tract; it can also be found in the flora of the skin, respiratory system and genitourinary system. In persons with lowered immunity this fungus may become a pathogen.

A conclusive diagnosis of bezoars in the urinary tract in not easy. Growing a microbiological culture of the pathogen from the blood and urine and determining predisposing factors facilitate diagnosis. Diagnostic imaging is also invaluable. However, radiological confirmation of the presence of fungus balls is not conclusive and may be imitated by other pathological structures: blood clots, urinary calculi, air bubbles, inflammatory lumps and epithelial tumours. In an ultrasound scan (ultrasonography examination), fungal bezoars are typically characterized by hyperechogenicity, less commonly hypoechogenicity, especially in weakened patients or those with lowered immunity [2].

Mycosis in the upper urinary tract usually manifests itself as an acute pyelonephritis, but may also 
cause renal abscesses or obstruction due to formation of concretions consisting of mycelium and necrotic fungal debris - fungal bezoars. Obstruction of the urinary tract stemming from the fact that the lumen is clogged with fungus is related to a systemic infection and haematogenous dissemination of the pathogen; it may also be caused by an ascending infection. Often the first symptoms of bezoars in the urinary tract include pain in the lumbar region, abdominal pain, turbid urine and oliguria or anuria; hydronephrosis and postrenal acute kidney injury may also occur [3]. The key to therapeutic success is to commence effective treatment as soon as possible. Pharmacological antifungal therapy is typically employed, using preparations available on the market, such as liposomal formulation of amphotericin B, flucytosine and azole derivatives, e.g. fluconazole, voriconazole or itraconazole. It often results in a complete recovery, but sometimes it is necessary to perform nephrostomy and urinary tract irrigation using solutions of antifungal drugs. As a last resort, fungal mass is surgically removed or a radical nephrectomy is performed $[4,5]$. Figure 1 shows the possible treatment methods for fungal bezoars in the urinary tract.

The authors presented selected case examples of patients in whose bodies bezoars with a fungal aetiology formed in the urinary tract, highlighting the main symptoms reported by the patients and diagnostic and treatment methods employed by physicians.

\section{Diabetes as a predisposing} factor for fungal infections

Diabetes is one of the diseases characterized by increased susceptibility to fungal infections. Fungal infections in diabetic patients are more severe, particularly in persons with uncontrolled glycaemia. Due to the fact that glucose is improperly used by cells, mechanisms responsible for immunity and maintaining balance in bacterial and fungal flora become impaired. Disorders of chemotaxis and phagocytosis performed by white blood cells facilitate opportunistic infections and increase their severity by limiting the natural "selfhealing" abilities of the body. Favourable conditions in the bodies of diabetic patients (damage to peripheral nerves and vessels) often lead to an asymptomatic development and growth of fungi. Long-term high levels of glucose in the body's secretions and excretions predispose towards high growth of Candida spp. fungi.

Hyperglycaemia in diabetic patients negatively affects blood plasma proteins. Functioning of proteins in the body is impaired as a result of their glycation [6]. These changes also affect proteins in the complement system, mostly complement component 3 (C3). It is suggested that glycation of the $\mathrm{C} 3$ protein impairs

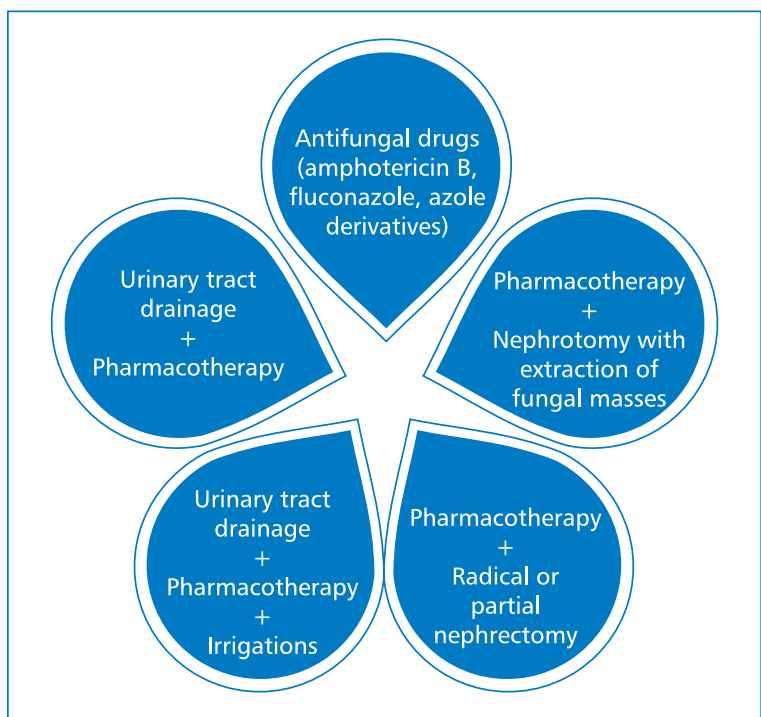

Figure 1. Treatment methods for bezoars in the urinary tract with a fungal aetiology

their ability to bind to bacterial surfaces and therefore weakens the intensity of the process of opsonisation, which plays a crucial role in phagocytosis.

Moreover, in case of patients with type 1 diabetes, the balance between regulatory $T$ lymphocytes (Tregs) and Th17 helper lymphocytes is disrupted, promoting chronic systemic inflammatory response and impairing proper response of the immune system. It appears that the fungi of species Candida albicans have an ability to express on the surface of their cells protein which are structurally and functionally homologous to receptors on phagocytes in mammals. Chronic hyperglycaemia intensifies their synthesis and expression, which in turn leads to increased binding of C3 protein to the aforementioned receptors and in effect disables immune response against the pathogen. The body does not recognize the fungal cells as foreign and fails to eliminate them. This particular type of molecular mimicry facilitates colonization and promotes the spread of infection throughout the body [6, 7].

Damage to the epidermis and impaired healing of wounds and ulcers, common among diabetic patients, are also not without significance for the pathogenesis of fungal infections in this population; they constitute perfect entry points for infections and form a favourable environment for fungal growth. Fluctuations in the blood glucose levels constitute a negative prognostic factor for treatment effectiveness of such dermatological changes as vaginal thrush, tinea or oral thrush. It is worth remembering that proper diabetic treatment and hygiene are the only effective preventive measures against opportunistic infections for this group of patients [8]. 


\section{Fungal bezoars in the urinary tract}

\section{- Candida spp. infection}

Opportunistic fungal infections of the urinary tract in diabetic patients are most often caused by a Candida spp. infection. They are typically asymptomatic or oligosymptomatic (oedemas, high blood pressure, pain in the lumbar region, turbid urine or haematuria). Rarely, they may cause postrenal acute kidney injury, with symptoms of oliguria or complete anuria, due to the fact that a bezoar composed of mycelial tissue had formed in the renal collecting system. Several selected cases confirming that a Candida spp. infection may cause postrenal acute kidney injury due to bezoar forming in the urinary tract of the patients are presented below.

In 1988, a group of physicians, led by Doemeny [3], presented the history of a 65-year-old woman with diagnosed diabetes, who was being treated with antibiotics due to urolithiasis. The patient had been reporting pain in the right hypochondrium and intermittent lowgrade fevers. Imaging revealed calcified deposits in the right kidney. The patient was prepared for lithotripsy, but a retrograde pyelogram performed on the day before the procedure revealed new abnormalities in the right renal pelvis, which were not found 6 months earlier. A CT examination suggested the presence of a mass of soft tissue. The fact that there was no dense focus present in the renal pelvis excluded urolithiasis as a cause of the symptoms. Microbiological examination of urine yielded negative results. Fungal colonies of species Torulopsis glabrata (also known as Candida glabrata) were grown and identified in the biopsy outcome obtained from the patient's right kidney. Histopathology excluded neoplastic lesions. It was decided to perform irrigation (utilizing amphotericin B) of the patient's urinary tract. No reduction in the size of the fungal bezoar in the renal pelvis was observed after 15 days of treatment; it was therefore decided to perform percutaneous extraction of fungal masses under epidural anaesthesia. A follow-up nephrogram performed 4 days after the procedure revealed no abnormalities [3].

Haruyama et al. [9] described a clinical case of a 69-year-old man with diabetes and neurogenic bladder dysfunction, admitted to hospital due to fever and acute kidney injury. The patient had been hospitalized 5 weeks earlier for similar symptoms. Antibiotic therapy using vancomycin had been administered at that time, but resulted in no significant improvement of health. Laboratory examination of obtained urine and blood samples indicated pyuria, systemic inflammation and disseminated intravascular coagulation (DIC). A computed tomography (CT) examination revealed an urinary calculus, hydronephrosis and increased uptake of the scintigraphic marker by the left kidney. Microbiological examination of blood, saliva and urine allowed to isolate fungus of Candida glabrata species. Pharmacotherapy was commenced using micafungin at a dose of $150 \mathrm{mg} /$ day and gabexate mesilate, a serine protease inhibitor. The treatment caused the symptoms to regress and the deposit in the left ureter to be excreted. However, three weeks later, during a follow-up ureteroscopy, a yellowish-white fungal bezoar was found in the same spot where the urinary calculus had been located earlier. In this patient's case, neurogenic bladder, poorly managed diabetes and prior long-term vancomycin therapy were alike to cause a fungal infection, in the treatment of which micafungin brought good results [9].

One of the most recent (2015) reports describes the case of a 53-year-old man with type 2 diabetes, where a formation of a fungal bezoar was followed by a subsequent emphysematous cystitis. The patient was admitted to the nephrology ward due to intermittent turbid urine which had been occurring for approximately 9 years and recently intensified. Treatment so far included various broad-spectrum antibiotics, which caused symptoms to subside. Over the 9 years during which the symptoms had persisted, fungal organisms had been detected twice during urinalysis. The man was subjected to ultrasound diagnostic imaging, which allowed to reveal a round, stationary during changes in body position, moderately hypoechoic structure measuring $3.5 \times 2.0 \mathrm{~cm}$ on the left bladder wall. A CT of the abdomen indicated presence of a structure characterized by poor absorption of radiological marker during excretory phase, a large gas collection in the bladder and a calcification in the right distal ureter measuring $1.1 \times 0.9 \mathrm{~cm}$ causing its enlargement and leading to a moderate hydronephrosis. Large amount of neutrophils and hyphae, microbiologically identified to be of Candida tropicalis species, was found during urinalysis. Based on the these results, the man was diagnosed with fungal infection with presence of a bezoar; intravesical irrigations using saline were commenced and led to excretion of a large amount of floccules from the bladder. A follow-up ultrasound examination showed a reduction in the size of the bezoar to $1.6 \times 0.8 \mathrm{~cm}$. In order to remove its remnants and crumble the calcification observed in the right ureter, lithotripsy was performed. Cystoscopy allowed to determine the actual size of the bezoar $(1.5 \times 1.0 \mathrm{~cm})$ and revealed inflammation and congestion of the bladder mucosa, as well as the fact that, in the vicinity of the bezoar, it was covered with biofilm from the mycelium. Histopathology of the obtained material showed chronic 
inflammation of the bladder mucosa, hyperkeratosis and squamous metaplasia. Initial intravenous therapy using fluconazole was decided, followed by continued administration of the drug orally at half the dose. Follow-up urine culture yielded negative results. The patient was discharged and prescribed continued 3-week therapy using fluconazole p.o. and strict control of glycaemia. Microbiological examination of urine performed 2 months later did not indicate increased pathogen levels and TC did not show the presence of gas in the bladder [10].

Comiter et al. [11] described a similar case of a 40-year-old man with bladder wall rupture due to emphysematous cystitis caused by the presence of a fungal bezoar obstructing the internal urethral orifice. The patient had been undergoing insulin therapy for many years due to advanced type 2 diabetes complicated by paraplegia. Medical history included skin ulceration over the trochanter, episodes of ketoacidosis, multiple urinary catheterizations using Foley catheters and multidrug antibiotic and antifungal therapy (ceftriaxone, vancomycin, ciprofloxacin, ticarcillin, fluconazole) due to urinary tract infections with various aetiologies (Proteus, Citobacter and Candida tropicalis). Since the clinical condition did not improve following administered treatment of the bladder infection, the patient was transferred to the Urology Clinic in Boston. Computer tomography showed bilaterally enlarged kidneys with hypodense foci consistent with pyelonephritis and a small amount of air in the bladder (which could have been secondary to catheterization). Due to the fact that the fever continued for another week, it was decided to administer amphotericin $B$ in the form of intravesical irrigations. Several days later, a followup CT was performed, revealing moderate bilateral hydronephrosis with unchanged image of hypodense foci in the kidneys and increased bladder distention. As intraperitoneal bladder perforation was suspected, it was immediately decided to perform exploratory laparotomy. A soft, round mass the size of a golf ball a fungal bezoar - was extracted from the bladder. A $1 \times 1 \mathrm{~cm}$ perforation of the bladder located on its anterolateral wall was also repaired. Improvement in the clinical condition of the patient was observed shortly after the procedure. Microbiological cultures of the surgically removed material revealed presence of Candida tropicalis fungus. Antibiotic therapy and amphotericin B were included in the patient's treatment regimen for two weeks, after which time the catheter was removed and the patient was discharged and prescribed oral fluconazole therapy for another two weeks. Follow-up TC showed that the changes in the bladder and kidneys subsided completely [11].
Shimada et al. [12] described a case of a 73-year-old man admitted to a clinical hospital in Sendai, Japan, due to acute kidney injury. Three years prior, the patient had been diagnosed with diabetes (improperly treated, unmanaged). The patient also had a neoplastic disease, prostate cancer at an early clinical stage, effectively treated for two years using hormone preparations - gonadoliberin. Main symptoms reported by the patient included: loss of appetite lasting for several days, general fatigue and weakness, lower abdominal pain and episodes of vomiting. These symptoms had earlier caused the patient to consult his family physician, who had prescribed an oral antibiotic therapy and catheterization of the neurogenic bladder 5 times a day. Biochemical laboratory tests performed at the hospital showed the following abnormal results: urea nitrogen $122 \mathrm{mg} / \mathrm{dl}$, creatinine $4.0 \mathrm{mg} / \mathrm{dl}$, plasma potassium level $7.6 \mathrm{mEq} / \mathrm{l}$, C-reactive protein (CRP) $27.9 \mathrm{mg} / \mathrm{dl}$, glycated haemoglobin $\left(\mathrm{HbA}_{1 \mathrm{c}}\right) 9.2 \%$. Urinalysis revealed numerous leukocytes per high power field. Ultrasound examination of the abdomen showed bilateral hydronephrosis with concurrent obstruction of the upper urinary tract. Following administration of intravenous fluid and antibacterial therapy, renal function deteriorated. Only nephrostomy using a percutaneous catheter allowed to confirm the presence of a soft tissue mass (bezoars) in renal pelvises of both organs. Fungus of Candida albicans species was isolated from microbiological culture of urine collected from an intrapelvic catheter (the number of colony-forming units was $10^{4} \mathrm{CFU} / \mathrm{ml}$ ). It was decided to begin antifungal therapy using fluconazole (200 mg/day IV) and perform irrigations using saline via a nephrostomy catheter; after 20 days of treatment, ureteral patency and proper renal function were restored [12].

A group of Spanish physicians led by Pazos [13] presented a case of candidiasis of the urinary tract resulting in obstruction and renal insufficiency in a 23-year-old woman with type 1 diabetes. The patient had been having chronic, recurring infections of lower urinary tract for approximately six months. Each of those infections had been treated using various broad-spectrum antibiotics, resulting in short-term improvement in the patient's clinical condition. Following admission to the hospital, the patient complained of having been unable to urinate for the past 24 hours, nonspecific abdominal pain and excreting fragments of necrotic tissue from the urethra when straining during urination. Basic laboratory tests were performed and showed the following deviations: microcytic anaemia (haemoglobin $7.2 \mathrm{~g} / \mathrm{l}$; haematocrit $21 \%$; iron level $75 \mu \mathrm{g} / \mathrm{ml}$; ferritin $144 \mathrm{ng} / \mathrm{ml})$, leucocytosis (10700 cells $/ \mathrm{ml})$, neutrophilia (75\%), hypoglycaemia (74 mg/dl); urea level was 
$314 \mathrm{mg} / \mathrm{dl}$; creatinine $6.4 \mathrm{mg} / \mathrm{dl}$; potassium level $5.7 \mathrm{mEq} / \mathrm{l}$. Urinalysis reveald presence of leukocytes (40-50 per high power field), erythrocytes (30-40 per high power field) and protein ( $4 \mathrm{~g} /$ day). Serological tests were also performed in order to confirm infection with hepatitis $B$ and $C$ viruses as well as human immunodeficiency virus (HIV). However, infection with these pathogens was excluded. Ultrasound examination of the abdomen revealed bilateral hydronephrosis and a tumour in the bladder measuring $6 \mathrm{~cm} \times 4.7 \mathrm{~cm}$. A catheter was introduced into the patient's bladder in order to restore normal excretion of urine; the patient was given fluconazole at a dose of $100 \mathrm{mg} / \mathrm{day}$ and ciprofloxacin $500 \mathrm{mg}$ every 12 hours. Cytology test performed on cells collected from the bladder did not confirm malignant neoplastic growth. Conversely, microbiological examination revealed high growth on culture media of Candida albicans fungus and Enterobacter spp. bacteria. After applying local anaesthetic, the tumorous formation was endoscopically removed from the bladder and ultimately identified as a bezoar formed as a result of a fungal infection of the urinary tract [13].

Sometimes, intensified haematuria may be the first symptom of a fungal bezoar formed in the urinary tract. Potel et al. [14] presented a clinical case of a 66-yearold man with insulin-dependent diabetes, mild renal insufficiency and peripheral vascular disease, in whose body a bezoar formed in the urinary tract. The patient was admitted to the hospital with painless haematuria which began 4 days after a left above-knee amputation. An intravenous pyelogram (IVP) was performed and showed delayed excretion of the contrast medium by the right kidney and bilateral filling defects in the pelvicalyceal system. Ultrasound examination revealed mild hydronephrosis and the presence of moderately hyperechoic tissue masses within renal pelvises. Microbiological assessment of collected urine sample allowed to identify a fungus of Candida albicans species. Necrotic tissue, blood cells and hyphae were found in material obtained directly from renal pelvises through percutaneous nephrostomy. Percutaneous extraction of fungal masses had to be performed twice. Intravenous therapy using amphotericin B was administered for 6 weeks, followed by fluconazole for the subsequent 6 months [14].

\section{Fungal bezoars in the urinary tract - Aspergillus spp. infection}

Mycosis caused by infection with saprophytic Aspergillus spp. fungi, which are commonly found in the environment, mainly in soil and food, typically occurs in persons who are immunocompromised, chronically abuse alcohol, are diabetic or chronically catheterized. Aspiration of the conidia of the fungus by an immunocompetent person rarely causes symptoms; however, in immunosuppressed patients it may lead to invasive aspergillosis. Species belonging to genus Aspergillus most commonly found in the environment include Aspergillus fumigatus, Aspergillus flavus and Aspergillus Niger. They are the underlying cause of the disease in $98 \%$ of cases. Aspergillosis includes the following types of the disease: allergic, chronic and invasive. Invasive type is the most severe clinical manifestation of aspergillosis [15, 16]. It most commonly locates itself in the lungs, less often in trachea, the bronchi and the sinuses. It may also, as multiorgan aspergillosis, infect the central nervous system, kidneys, skin, heart, eyes or thyroid. Kidneys are usually infected via haematogenous dissemination from another organ invaded by Aspergillus. Over the course of aspergillosis, multiple purulent infection foci form in the kidneys. Formation of Aspergillus bezoars in the urinary tract causing obstruction and postrenal acute kidney injury is a very rare clinical case and typically affects one ureter [16, 17].

Indian scientists described a case of a 48-year-old woman with diabetes whose left ureter was completely obstructed as a consequence of presence of a Aspergillus fungal bezoar. The patient's medical history included dull pain in the left flank, recurrent urinary tract infections as well as excretion of small fragments of necrotic tissue with urine during strong micturition over the previous two years. Microbiological examination of obtained urine sample confirmed aspergillosis of the urinary tract. Imaging (intravenous urography and $\mathrm{CT}$ ) showed hydronephrosis in the left kidney. Conglomerates of fungal tissue were removed from the ureter and renal pelvis via ureteroscopy. Microscopic examination of the biological material revealed the presence of hyphae with conidiophores, which allowed to conclusively diagnose the patient with aspergillosis. The patient was prescribed oral pharmacotherapy using itraconazole at a dose of $400 \mathrm{mg}$ for one month as well as irrigations using an amphotericin B solution via a catheter which was previously inserted into the ureter for 7 days. Retrograde urography performed on the $10^{\text {th }}$ day after the procedure showed no pathological changes in the left kidney [18].

The case described in 2013 by Iranian physicians led by Najafi [19] also concerned a patient in whose body Aspergillus fungal bezoar formed in the urinary tract. A 45-year-old man with properly managed diabetes reported to the hospital complaining of mild pain in the left lumbar region, dysuria and intermittent strong abdominal pain during an increased strain while urinating. The patient also noticed that during voiding, apart 
from turbid urine, whitish tissue masses are also excreted from the urethra. Three months prior to current admission to the hospital, the patient had undergone lithotripsy; a catheter had also been inserted into the ureter for three weeks. Due to pyuria observed during urinalysis, antibiotics were administered. Ultrasound examination of the abdomen revealed presence of a hyperechoic structure in the left renal pelvis. The patient was catheterized. Biochemical examination showed an increased creatinine and urea nitrogen levels in the blood serum. A fungus of Aspergilla terreus sepcies was grown from the biological material collected from the removed catheter. Conclusive diagnosis was formed after a polymerase chain reaction assay, DNA sequencing and comparison of results of genetic tests with reference data from the GenBank database. The patient was prescribed antifungal therapy: initially itraconazole, orally (400 mg/day) for 7 days; however, due to intolerance, the dose was halved. Despite that, the drug was replaced after 25 days (continued deterioration in renal function) with voriconazole administered per os for the next 3 months at a dose of $400 \mathrm{mg} /$ day. After 6 months of continued antifungal treatment and several endoscopies, the fungal bezoar was removed from the urinary tract and renal function and perfusion returned to normal [19].

\section{Fungal bezoars in the urinary tract - infection with other species of fungi}

In recent years, mycoses caused by moulds of Mucor, Absidia and Rhizopus genera are increasingly more frequent in hospital wards [20]. Genus Rhizopus consists of filamentous fungi; certain species produce mycotoxins, chemical compounds toxic to the human body [21]. Moulds are widespread in the environment: they can be found in soil, on dead, decaying plant and animal remains and on food products; their spores float in the air. Infection is a result of inhaling the spores into the respiratory tract and paranasal sinuses, from where the fungi travel to the central nervous system. Symptoms of mucormycosis typically develop in persons with immune system disorders and are generally severe, with multiple organs invaded (lungs, paranasal sinuses, brain, skin) $[22,23]$. Risk factors for the disease also include: diabetes, metabolic acidosis, steroid therapy, hematologic diseases, organ transplantations, iron overload, intravenous drug use and AIDS [24]. Prognoses of mucormycoses are poor, with mortality ratesup to $70-100 \%$. It is worth noting that mould infections may also occur in persons with properly functioning immune system as a result of the fungus directly penetrating into damaged tissues $[22,23]$.
Renal zygomycosis is typically secondary to haematogenous dissemination of the fungus from other focus within the body [25, 26]. In 2010, Palacio-Bedoya et al. [27] described a case of a fungal bezoar caused by Rhizopus oryzae infection located in the renal collecting system, which, atypical for such aetiology, was not accompanied by parenchymal invasion. A 32-yearold patient treated for diabetes was admitted to the ward due to macroscopic haematuria, which had been continuing for two months, associated with recurring pain in the lumbar region, oliguria and loss of $45 \mathrm{~kg}$ of body weight without fever, chills or night sweats; the patient also reported inability to urinate and, when straining, excreting 10 centimetre long fragments of brown necrotic tissue from the urethra. The following abnormalities were observed during laboratory tests: leukopenia, anaemia (haemoglobin $6.8 \mathrm{mg} / \mathrm{dl}$ ), reduced haematocrit (19.8\%) and thrombocytosis (132 thousand cells/ml). Glycaemia on admission was $227 \mathrm{mg} / \mathrm{dl}$, and $\mathrm{HbA}_{1 \mathrm{c}}$ of 14.1 indicated considerable lack of diabetes management over the previous several months. Urinalysis of yellow, turbid urine revealed high content of protein, glucose, red blood cells and isolated bacteria. Urine as also tested for cocaine content; the result was positive. The patient underwent cystoureteroscopy with partial extraction of a large yellow tissue mass from the ureter and the renal pelvis, nephrostomy tube was also placed. Oral therapy using fluconazole (200 mg/day) was commenced. On the second day of the therapy, percutaneous endoscopy was performed and resulted in removal of a large fungal bezoar. Rhizopus oryzae fungus species was grown from samples collected for examination. Pale grey colonies grew rapidly at $25^{\circ} \mathrm{C}$, filling the Petri dish in 3 days. Minimum inhibitory concentration (MIC) for posaconazole and amphotericin B was equal to 2.0 and $0.25 \mu \mathrm{g} / \mathrm{ml}$, respectively, hence the antifungal preparation used up until now was changed to amphotericin $B$ lipid complex $(5 \mathrm{mg} / \mathrm{kg}$ ) and amphotericin B deoxycholate $(50 \mathrm{mg} / \mathrm{l}$ of water) administered via nephrostomy every 8 hours for 9 days. After that time, the patient was discharged at his own request. Oral therapy was continued for 4 weeks, but due to toxic effects of the drug (deterioration in renal function with an increase in creatinine level) it was replaced with posaconazole ( $400 \mathrm{mg}$ orally, twice daily) and continued for another 5 months. The patient showed no symptoms of a recurrence and did not require additional antifungal pharmacotherapy 5 years after the treatment [27].

\section{Summary}

Fungal bezoars in the urinary tract are an exceptionally rare complication of fungal infections of the 
urinary tract in diabetic patients. They are most often the result of an infection with Candida spp., less frequently Aspergillus spp. and other fungi. Examples of medical histories of patients in whose bodies fungal bezoars formed presented in this paper confirm the importance of early diagnosis and commencing effective treatment quickly in order to increase survival rate and improve prognosis of diabetic patients. Due to peripheral sensory disorders, common in this patient group, the initial pain symptoms may be missed; it is therefore worth remembering that oliguria, anuria or a sudden deterioration in renal function may be the symptoms of a fungal bezoar formed in the urinary tract. It should also be remembered that fungal infections in diabetic patients, particularly when diabetes is uncontrolled and unmanaged, may be fulminant and require a more radical treatment approach - from standard antifungal pharmacotherapy, through nephrostomy with irrigations of the urinary tract, up to and including partial or radical nephrectomy.

\section{REFERENCES}

1. Taczalska A, Nowosławska-Łuniewska K, Koziarkiewicz M et al. Bezoary - trudności diagnostyczne na przykładzie własnych obserwacji i przegląd piśmiennictwa. Dev Period Med 2013; 17: 265-269.

2. Di Paola G, Mogorovich A, Fiorini G et al. Candida bezoars with urinary tract obstruction in two women without immunocompromising conditions. Scientific World Journal 2011; 11: 1168-1172.

3. Doemeny JM, Banner MP, Shapiro MJ et al. Percutaneous extraction of renal fungus ball. AJR Am J Roentgenol 1988; 150: 1331-1332.

4. Ku JH, Kim ME, Jeon YS et al. Urinary ascites and anuria caused by bilateral fungal balls in a premature infant. Arch Dis Child Fetal Neonatal Ed 2004; 89: F92-93.

5. Pappas PG, Kauffman CA, Andes DR et al. Clinical Practice Guideline for the Management of Candidiasis: 2016 Update by the Infectious Diseases Society of America. Clin Infect Dis 2016; 62: e-e50.

6. Drozdowska A, Drzewoski J. Mycoses in diabetes - difficult diagnostic and therapeutic problem. Review of literature. Diabetol Dośw Klin 2008; 8: 1-11.

7. Ryba-Stanisławowska M. Zaburzenia regulacji reaktywności zapalnej w patogenezie cukrzycy typu 1: postępy patofizjologii i możliwość nowego rodzaju leczenia. Med Metab 2015; 19 : 50-63.

8. Tatoń J. Profilaktyka zespołu stopy cukrzycowej oparta na patofizjologii. Med Metab 2014; 18: 76-82.

9. Haruyama N, Masutani K, Tsuruya K et al. Candida glabrata fungemia in a diabetic patient neurogenic bladder: successful treatment with micafungin. Clin Nephrol 2006; 66: 214-217.

10. Wang $L$, Ji X, Sun GF et al. Fungus ball and emphysematous cystitis secondary to Candida tropicalis: A case report. Can Urol Assoc J 2015; 9: 683-686.

11. Comiter CV, McDonald M, Menton J, Yalla SV. Funcal bezoar and bladder rupture secondary to Candida tropicalis. Urology 1996; 47: 439-441.

12. Shimada S, Nakagawa $H$, Shintaku I et al. Acute renal failure as a result of bilateral ureteral obstruction by Candida albicans fungus balls. Int J Urol 2006; 13: 1121-1122.

13. Pazos R, Esteban J, Pérez $C$ et al. Bilateral hydronephrosis caused by a "fungus ball". Nefrologia 2001; 21: 319-320.

14. Patel B, Khosla A, Chenoweth JL. Bilateral fungal bezoars in the renal pelvis. Br J Urol 1996; 78: 651-652.

15. Latgé JP. Aspergillus fumigatus and aspergillosis. Clin Microbiol Rev 1999; 12: 310-350.

16. Wosiewicz P, Hartleb M, Kochel-Jankowska A et al. Inwazyjna aspergiloza u chorych z marskością wątroby. Gastroenterol Prakt 2014; 4: 62-66.

17. Gupta KL. Fungal infections and the kidney. Indian J Nephrol 2001; 11: 147-157.

18. Ahuja A, Aulakh BS, Cheena DK et al. Aspergillus fungal balls causing ureteral obstruction. Urol J 2009; 6: 127-129.

19. Najafi N, Shokohi T, Basiri A et al. Aspergillus terreus-related ureteral obstruction in a diabetic patient. Iran J Kidney Dis 2013; 7: 151-155.

20. Siczyńska B, Dyk D. Wybrane aspekty szpitalnych zakażeń grzybiczych. Pielęg Chir Angiol 2013; 1: 1-6.

21. Pałys M, Targoński Z. Produkcja kwasu mlekowego przez grzyby z rodzaju Rhizopus. Żywn Nauka Technol Jakość 2013; 4: 21-36.

22. Biliński P, Seferyńska ., Warzocha K. Diagnostyka i leczenie układowych zakażeń grzybiczych w onkohematologii. Onkol Prakt Klin 2008; 4: 15-24.

23. Garczewska B. Szpitalne zakażenia grzybicze. In: Dzierżanowska D (ed). Zakażenia szpitalne. $\alpha$-medica press, Bielsko-Biała 2008; 409-425.

24. 24. Ribes JA, Vanover-Sams CL, Baker DJ. Zygomycetes in human disease. Clin Microbiol Rev 2000; 13: 236-301.

25. Lussier N, Laverdiere M, Weiss K et al. Primary renal mucormycosis. Urology 1998; 52: 900-903.

26. Weng DE, Wilson WH, Little R et al. Successful medical management of isolated renal zygomycosis: case report and review. Clin Infect Dis 1998; 26: 601-605.

27. Palacio-Bedoya F, Cadena JA, Thompson GR et al. A noninvasive renal fungus ball caused by Rhizopus - a previously unreported manifestation of zygomycosis. Med Mycol 2010; 48: 866-869. 